\title{
Silencing the IncRNA NORAD inhibits EMT of head and neck squamous cell carcinoma stem cells via miR-26a-5p
}

\author{
WEIMING HU $^{1 *}$, YONG ZHAO ${ }^{2 *}$, LIZHONG SU $^{1}$, ZULIANG WU $^{1}$, \\ WENJING JIANG ${ }^{1}$, XIAOZE JIANG ${ }^{1}$ and MING LIU ${ }^{3}$ \\ ${ }^{1}$ Department of Otorhinolaryngology, Zhejiang Provincial People's Hospital, People's Hospital of \\ Hangzhou Medical College, Hangzhou, Zhejiang 310014; ${ }^{2}$ Department of Otorhinolaryngology, \\ XIXI Hospital of Hangzhou; ${ }^{3}$ Department of Otorhinolaryngology, \\ Zhejiang Hospital, Hangzhou, Zhejiang 310012, P.R. China
}

Received July 22, 2020; Accepted December 3, 2020

DOI: $10.3892 / \mathrm{mmr} .2021 .12383$

\begin{abstract}
Cancer stem cells are closely associated with tumor metastasis or recurrence. According to previous literature reports, microRNA (miR)-26a has an inhibitory effect on head and neck squamous cell carcinoma (HNSCC), and the long non-coding RNA (lncRNA) non-coding RNA activated by DNA damage (NORAD) has been found to interact with miR-26a-5p. The present study aimed to investigate the regulation and mechanism of NORAD and miR-26a-5p in the epithelial-mesenchymal transition (EMT) of HNSCC stem cells. An ALDEFLUOR stem cell detection kit, a flow cytometer, a self-renewal ability test and western blotting were used to sort and identify HNSCC stem cells. The ENCORI website and a dual-luciferase assay were used to assess the relationship between genes. The mRNA and protein expression levels of NORAD, miR-26a-5p and EMT-related genes were detected via reverse transcription-quantitative PCR and western blotting. Functional experiments (MTT assay, flow cytometry, wound healing assay and Transwell assay) were conducted to analyze the effects of NORAD and miR-26a-5p on HNSCC stem cells. The successfully sorted aldehyde dehydrogenase $(\mathrm{ALDH})^{+}$cells had a self-renewal capacity and displayed upregulated expression levels of CD44, Oct-4 and Nanog. NORAD knockdown, achieved using small interfering (si) RNA, downregulated the expression levels of tumor markers in $\mathrm{ALDH}^{+}$cells. siNORAD inhibited cell vitality, migration and invasion, as well as promoted apoptosis, increased
\end{abstract}

Correspondence to: Dr Ming Liu, Department of Otorhinolaryngology, Zhejiang Hospital, 12 Lingyin Road, Xihu, Hangzhou, Zhejiang 310012, P.R. China

E-mail: liuming_ml1@163.com

${ }^{*}$ Contributed equally

Key words: head and neck squamous cell carcinoma, stem cells, epithelial-mesenchymal transition, long non-coding RNA, non-coding RNA activated by DNA damage, microRNA-26a-5p the expression of epithelial cell markers and decreased the expression of interstitial cell markers in HNSCC stem cells. miR-26a-5p was a downstream gene of NORAD, and knockdown of miR-26a-5p partially offset the regulatory effect of siNORAD on HNSCC stem cells. Collectively, the present study demonstrated that NORAD knockdown attenuated the migration, invasion and EMT of HNSCC stem cells via miR-26a-5p.

\section{Introduction}

Head and neck squamous cell carcinoma (HNSCC) accounts for $\sim 6 \%$ of systemic malignancies, and there are $\sim 600,000$ new cases and 350,000 mortalities worldwide each year $(1,2)$. The past decade has seen an improved survival of patients with HNSCC due to the application of new drugs and treatments; however, the overall survival rate has remained almost unchanged (3). The main reason for treatment failure is distant metastasis or local recurrence of the tumor (4).

In recent years, previous studies both in China and abroad have reported that the existence of stem cells is the main cause of tumor metastasis and recurrence (5). Stem cells are a group of cell subpopulations that self-renewal, differentiation and passage abilities (6). These cells have been discovered and confirmed to be present in numerous blood tumors and solid tumors, such as leukemia, prostate cancer, breast cancer and head and neck tumors, amongst others (7-9). In laboratory and clinical studies, these cells demonstrated tolerance to traditional therapies, including surgery, radiotherapy and chemotherapy (10). The identification of tumor stem cell biomarkers may help to develop individualized chemotherapy drugs for targeted treatment of tumor stem cells.

CD44, aldehyde dehydrogenase (ALDH), Oct-4 and Nanog have all been proved to be useful for the isolation and identification of tumor stem cells in HNSCC (11). Chen et al (12) revealed that $\mathrm{ALDH}^{+}$and $\mathrm{CD} 44^{+}$cells collected from patients with HNSCC can resist radiation therapy and maintain tumor stem-like properties in HNSCC cells, serving a vital role in tumor maintenance and growth. Moreover, Prince et al (13) reported that cells exhibiting low levels of ALDH can induce tumors with the same morphology and heterogeneity as the 
primary tumor, and cells with high expression of ALDH can be passaged in animal models $(13,14)$. These characteristics are consistent with the nature of tumor stem cells, thus indicating that ALDH is a highly selective and specific marker for HNSCC stem cells.

According to the literature, microRNA (miRNA/miR)-26a serves a role in multiple diseases $(15,16)$. In animal experiments, miR-26a has been shown to inhibit the release of inflammatory factors and the activation of the NF- $\mathrm{\kappa B}$ pathway by targeting transient receptor potential cation channel subfamily $\mathrm{C}$ member 3, thereby slowing the progression of atherosclerosis in mice (17). In bladder cancer, miR-26a inhibits cell invasion by acting on the high mobility group AT-hook 1 protein (18). miR-26a can also act on its direct target gene fibroblast growth factor 9 to inhibit the proliferation and migration of gastric cancer cells (19). Furthermore, studies have reported that miR-26a has an inhibitory effect on HNSCC (20), while the long non-coding (lnc)RNA non-coding RNA activated by DNA damage (NORAD) has been found to interact with miR-26a through bioinformatics, and exert a cancer-promoting effect in various tumors (21).

Therefore, the aim of the present study was to investigate whether NORAD affects the proliferation, apoptosis, migration, invasion and epithelial-mesenchymal transition (EMT) of HNSCC cells by inhibiting the expression of miR-26a.

\section{Materials and methods}

Cells and culture. As recommended by the manufacturer, H357 cell lines (cat. no. 06092004) purchased from The European Collection of Authenticated Cell Cultures were cultured in a $37^{\circ} \mathrm{C}, 5 \% \mathrm{CO}_{2}$ environment in DMEM:F12 medium (cat. no. 30-2006) containing $2 \mathrm{mM}$ glutamine (cat. no. 30-2214), 10\% FBS (cat. no. 30-2020; all from the American Type Culture Collection), and $0.5 \mu \mathrm{g} / \mathrm{ml}$ sodium hydrocortisone succinate (cat. no. 125-04-2; Pure Chemistry Scientific, Inc.). HSC-3 cell lines (cat. no. JCRB0623) were purchased from the Japanese Collection of Research Bioresources Cell Bank, and cultured in Eagle's minimum essential medium (cat. no. 30-2003) with 10\% newborn calf serum (cat. no. 16010; both Gibco; Thermo Fisher Scientific, Inc.).

$\mathrm{ALDH}^{-}$cells and $\mathrm{ALDH}^{+}$cells from $\mathrm{H} 357$ and HSC-3 cell lines were sorted and identified using an ALDEFLUOR stem cell detection kit (cat. no. 01700; Stemcell Technologies, Inc.), according to the manufacturer's instructions, and a flow cytometer (FACScan; BD Biosciences) with BD CellQuest Pro software V5.1 (BD Biosciences) (22).

Self-renewal ability assay. ALDH ${ }^{-}$cells and $\mathrm{ALDH}^{+}$cells were cultured in common cell culture flasks in DMEM containing 10\% FBS. Cells in the logarithmic growth phase were selected, digested and then resuspended in serum-free medium containing $10 \mathrm{ng} / \mathrm{ml}$ EGF and $10 \mathrm{ng} / \mathrm{ml}$ basic fibroblast growth factor. Subsequently, the cells were seeded in a low-adhesion 6-well plate at a density of 2,500 cells $/ \mathrm{ml}$. After 3 days of culture, $50 \%$ of the culture medium was renewed. The self-renewal capacity of the cells was evaluated using the method described in the study by Ghods et al (23). The cell microspheres were collected using a $40-\mu \mathrm{m}$ filter, dispersed into a single-cell suspension and inoculated into a culture plate at a density of 1,000 cells/ml. After 5-7 days of culture, the morphology of the cell microspheres was imaged using a light microscope (magnification, x100). Cells that could form cell microspheres again were considered to be self-renewing.

Cell transfection. To investigate the function of NORAD in the development of HNSCC stem cells, NORAD overexpression and small interfering (si)RNA (siNORAD, 5'-AATAGAATGAAGACCAACCGC-3') vectors were transfected into $\mathrm{H} 357$ and HSC-3 cells, and empty vector negative control (NC) and siNC (5'-GCGCGATAGCGCGAATATA-3') were introduced as the NC. Subsequently, miR-26a-5p was identified as a potential downstream target of NORAD using ENCORI software (http://starbase.sysu.edu.cn/index.php). The effects of miR-26a-5p expression on the tumor growth were measured via the transfection of miR-26a-5p inhibitor (I, 5'-UUCUCCGAACGUGUCACGUTT-3') $(2 \mu \mathrm{g})$ or inhibitor control (IC, 5'-CAGUACUUUUGUGUAGUACAA-3') $(2 \mu \mathrm{g})$ using Lipofectamine ${ }^{\mathrm{TM}} 2000$ reagent (Invitrogen; Thermo Fisher Scientific, Inc.) at room temperature for $15 \mathrm{~min}$. After $48 \mathrm{~h}$ of incubation, the subsequent experiments were conducted. To verify the effects of the relationship between NORAD and miR-26a-5p on the development of HNSCC stem cells, miR-26a-5p I was applied for co-transfection with siNORAD in H357 and HSC-3 cells. All experiments in vitro contain six groups, including Blank, siNORAD-siNC, siNORAD, IC, I and siNORAD+I groups.

Western blotting. Western blot analysis was conducted as previously described (24). Total protein extraction from HNSCC stem cells was performed before and after transfection. Specifically, cells in the logarithmic growth phase were chosen, and after removal of the culture medium in the cell culture dish, the cells were washed three times with $4^{\circ} \mathrm{C}$ pre-chilled PBS solution for $\sim 5$ min each time. After the PBS solution was exhausted, RIPA lysis buffer (cat. no. C05-01001; BIOSS) was added and incubated on ice for $30 \mathrm{~min}$ to fully lyse the cells. Then, the cells were scraped off with a cell spatula, and transferred into a $1.5-\mathrm{ml} \mathrm{EP}$ tube together with the lysate, followed by $10 \mathrm{~min}$ of centrifugation at $4^{\circ} \mathrm{C}$ and $2,000 \mathrm{xg}$. After centrifugation, the supernatant was collected into an EP tube and was directly used in western blot analysis. Protein concentration was determined using a BCA protein assay kit (Bio-Rad Laboratories, Inc.). The specific steps of the western blotting, namely gel preparation, electrophoresis, membrane transfer (PVDF membrane; cat. no. IPVH00010; EMD Millipore), blocking (buffer; cat. no. 37565, Thermo Fisher Scientific, Inc.), incubation with primary antibodies for $24 \mathrm{~h}$ at $4^{\circ} \mathrm{C}$ ) and with secondary antibodies for $1 \mathrm{~h}$ at room temperature, and luminescence (ECL luminous fluid; cat. no. WBK1S0100; EMD Millipore; gel imaging system; Tanon 2500; Beijing Solarbio Science \& Technology Co., Ltd.), were performed to obtain the results.

All antibodies in this study were purchased from Abcam, and were as follows: CD44 (cat. no. ab157107; $81 \mathrm{kDa} ; 1: 2,000$ ); Oct-4 (cat. no. ab181557; $45 \mathrm{kDa} ; 1: 1,000$ ); Nanog (cat. no. ab109250; $37 \mathrm{kDa}$; 1:1,000); MMP-2 (cat. no. ab97779; 74 kDa; 1:1,000); MMP-9 (cat. no. ab38898; $92 \mathrm{kDa}$; 1:1,000); E-cadherin (cat. no. ab40772; $97 \mathrm{kDa}$ : 
1:10,000); N-cadherin (cat. no. ab18203; 100 kDa; 1:10,000); vimentin (cat. no. ab92547; 54 kDa; 1:1,000); GAPDH (cat. no. ab181602; 36 kDa; 1:10,000); and Goat Anti-Rabbit lgG H\&L (HRP-conjugated; cat. no. ab205718; 1:2,000).

Lentivirus transfection. NORAD was cloned into a pCDNA3 plasmid (Invitrogen; Thermo Fisher Scientific, Inc.). The construction of NORAD overexpression and NC lentivirus vectors, and the packaging of lentiviruses were all conducted by Shanghai GenePharma Co., Ltd. The sorted $\mathrm{ALDH}^{+} /{ }^{-} \mathrm{HNSCC}$ cells $\left(1 \times 10^{3}\right.$ cell) were seeded on a 96 -well plate for $24 \mathrm{~h}$ of regular culture. Then, when reaching $70 \%$ confluence, ALDH cells were infected with viruses (MOI, 10), and $\mathrm{ALDH}^{+}$cells were transfected with $10 \mu \mathrm{g}$ siNORAD or NORAD overexpression vector. The transfection of cells was carried out using Lipofectamine 3000. After $48 \mathrm{~h}$, subsequent experimentations were carried out.

Cell viability assay. An MTT cell proliferation and cytotoxicity assay kit (cat. no. C0009; Beyotime Institute of Biotechnology) was used to determine the effects of siNORAD and miR-26a-5p I on the viability of HNSCC stem cells. According to the experimental requirements, HNSCC stem cells $\left(1 \times 10^{4}\right.$ cells $\left./ \mathrm{ml}\right)$ were cultured at $37^{\circ} \mathrm{C}$ for 24,48 and $72 \mathrm{~h}$. Subsequently, $10 \mu \mathrm{l}$ MTT solution was added to each well, and the incubation was continued at $37{ }^{\circ} \mathrm{C}$ for $4 \mathrm{~h}$. Next, $100 \mu \mathrm{l}$ formazan lysis solution was added to each well. After mixing, the cells were incubated at $37^{\circ} \mathrm{C}$ for $3-4 \mathrm{~h}$ to dissolve formazan. The absorbance was measured at $570 \mathrm{~nm}$ using an iMark microplate reader (Bio-Rad Laboratories, Inc.).

Apoptosis assay. An Annexin V-FITC Apoptosis Detection kit (cat. no. C1062M; Beyotime Institute of Biotechnology) was used to analyze the apoptosis of HNSCC stem cells. Specifically, after $48 \mathrm{~h}$ of transfection, the collected cell microspheres were digested with trypsin and pipetted into a single cell suspension. Then, the cell suspension was centrifuged at $1,000 \mathrm{x} g$ for $5 \mathrm{~min}$ at room temperature and the supernatant was discarded. Next, $195 \mu 1$ Annexin V-FITC binding solution was added to gently resuspend the cells. Subsequently, $5 \mu \mathrm{l}$ Annexin V-FITC and $10 \mu \mathrm{l}$ PI staining solution were added in sequence, and the cells were incubated at room temperature $\left(20-25^{\circ} \mathrm{C}\right)$ for $10-20 \mathrm{~min}$ in the dark, and then placed in an ice bath. A flow cytometer (CytoFLEX V2-B4-R2; Beckman Coulter, Inc.) and Kaluza analysis V2.0 software (Beckman Coulter, Inc.) were used to detect the amount of apoptosis (percentage of early apoptotic cells + percentage of late apoptotic cells) in each group.

Wound healing assay. HNSCC stem cells of different groups were collected separately. After digestion, the supernatant was discarded and the cell suspension was subjected to centrifugation at $1,600 \mathrm{x}$ g for $20 \mathrm{~min}$ at room temperature. Then, the cells were resuspended in their respective culture solutions and subsequently pipetted into a single cell suspension $\left(3 \times 10^{5}\right.$ cells $\left./ \mathrm{ml}\right)$. Next, the cell suspension was seeded on a 6-well cell culture plate, so that the cells could reach the state of monolayer adherent growth and attain nearly $100 \%$ confluence the next day. When the cells adhered to the well, serum-free cell culture medium was added to culture the cells overnight at $37^{\circ} \mathrm{C}$. Then, the center of the 6 -well plate was scratched with a 200- $\mu 1$ sterile tip, with even force applied. The floating cells were washed with PBS and cultured in a serum-free medium. Images were captured under an inverted microscope (magnification, x100; CKX53; Olympus Corporation) at 0 and $48 \mathrm{~h}$ after scratching to observe the healing of cell scratches and to compare the healing rate of each group, which was calculated with the measurement values of the scratch distances of five randomly selected points. In total, three parallel holes were made in each group of cells, and the experiment was repeated three times.

Transwellassay.Thecellsuspensionwasresuspendedinaprepared 24-well plate invasion chamber (cat. no. 3455-024-01; Cultrex; R\&D Systems, Inc.) at a density of $5 \times 10^{4}$ cells $/ \mathrm{ml}$. The upper chamber surface was coated with Matrigel (cat. no. 354234; Corning, Inc.). About 10,000 cells were seeded into the upper chamber of the inserts supplemented with $70 \mu 1$ serum-free DMEM. Then, $750 \mu 1$ DMEM containing 10\% FBS was added as a chemical attractant to the lower chamber of the 24-well plate. The cell suspension was incubated for $48 \mathrm{~h}$. At the end of the incubation, the chamber was removed and the non-invasive cells in the upper chamber were wiped off with a sterile cotton swab. Invasive cells were stained with Giemsa stain (cat. no. G5637; Sigma-Aldrich; Merck KGaA) at room temperature for $10 \mathrm{~min}$, and the number of transmembrane cells, which were randomly selected from each field, was counted under an inverted light microscope (magnification, x250) for each membrane.

Target gene prediction and verification. The binding relationship between NORAD and miR-26a-5p was predicted using the Encyclopedia of RNA Interactomes website (http://starbase.sysu.edu.cn/).

The binding relationship between NORAD and miR-26a-5p was verified using a dual luciferase assay according to the following experimental steps: Luciferase reporter gene vectors (pmirGLO; cat. no. E1330; Promega Corporation) containing NORAD wild-type or mutant sequences were constructed. After screening positive clones and sequencing, the recombinant luciferase reporter gene vector was extracted, and then co-transfected with 200 ng miR-26a-5p I or IC into HNSCC stem cells using Lipofectamine 2000 reagent (Invitrogen; Thermo Fisher Scientific, Inc.), according to the manufacturer's instructions, for $48 \mathrm{~h}$ at $37^{\circ} \mathrm{C}$. After transfection for $36 \mathrm{~h}$, the dual-luciferase system (cat. no. D0010-100T; Beijing Solarbio Science \& Technology Co., Ltd.) and a detector (GloMax 20/20; Promega Corporation) were used to analyze the fluorescence intensity of the reporter gene. Luciferase activity of genes was normalized to that of Renilla luciferase.

Reverse transcription-quantitative $(R T-q) P C R$. To detect the expression levels of NORAD, miR-26a-5p and EMT-related genes, TRIzol ${ }^{\circledR}$ reagent (cat. no. 15596018; Invitrogen; Thermo Fisher Scientific, Inc.) was used to extract mRNA and miRNA, according to the manufacturer's instructions, and a NanoDrop system (cat. no. ND-LITE-PR; NanoDrop; Thermo Fisher Scientific, Inc.) was used to determine RNA concentration and purity. The RNA was then used to generate cDNA using a reverse transcription kit (OneStep RT-PCR kit; 
A

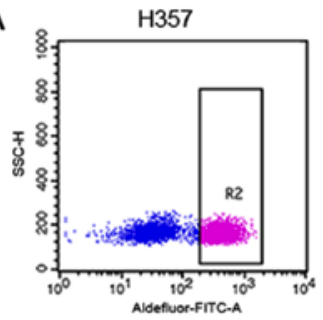

B

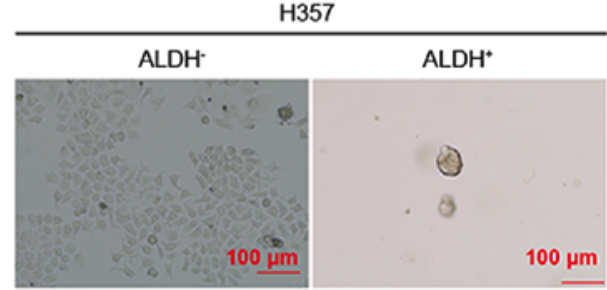

C

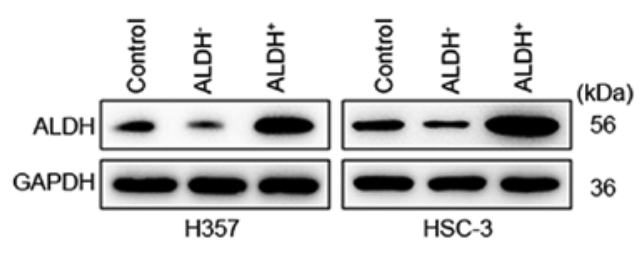

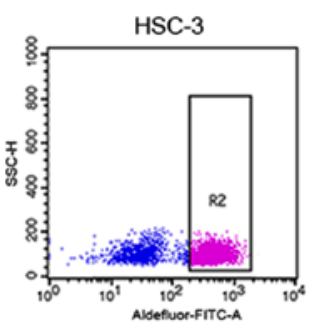

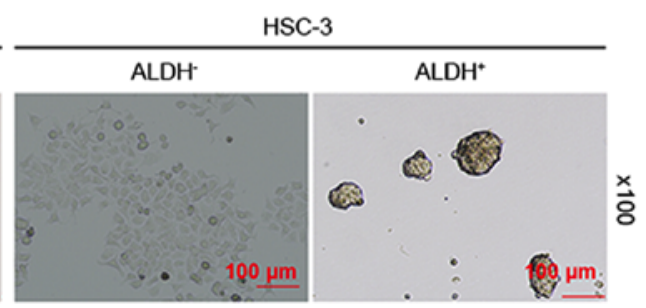

D

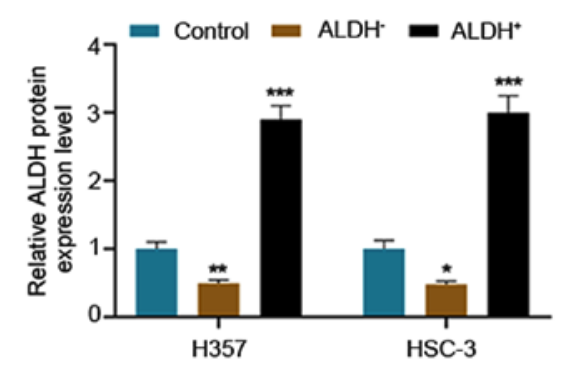

E

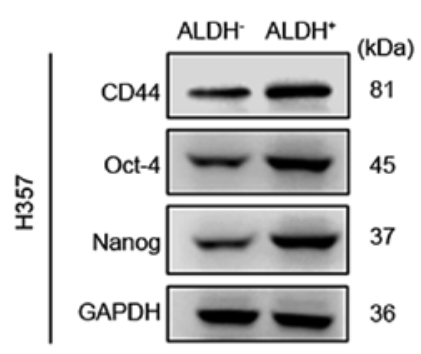

G

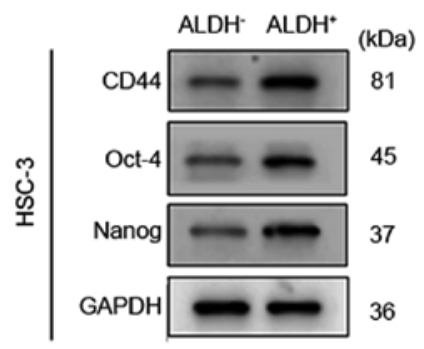

$\mathrm{F}$

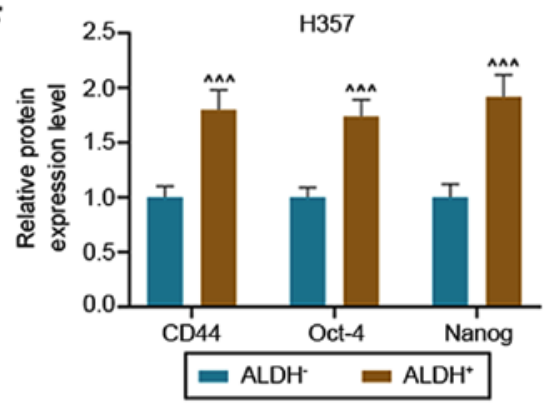

$\mathrm{H}$

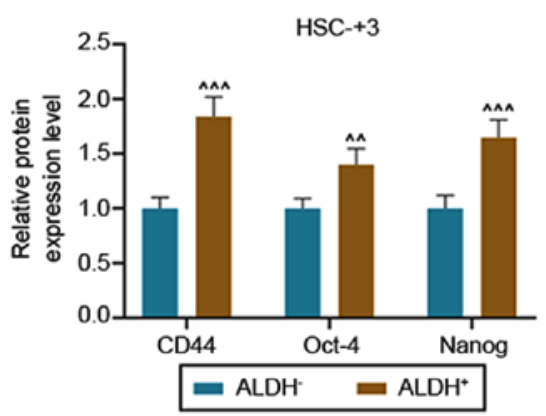

Figure 1. Isolation and identification of tumor stem cells from HNSCC cell lines. (A) Flow cytometry was used to sort ALDH and ALDH ${ }^{+}$cells from HNSCC cell lines H357 and HSC-3. (B) ALDH ${ }^{+}$cells suspended in serum-free medium formed cell microspheres (magnification, x100). (C) Protein expression levels of ALDH in control, $\mathrm{ALDH}^{-}$and $\mathrm{ALDH}^{+}$cells were detected using western blotting, (D) and the results were semiquantified. (E) Western blotting results of the (F) expression levels of tumor stem cell marker genes CD44, Oct-4 and Nanog in ALDH ${ }^{-}$and ALDH ${ }^{+} \mathrm{H}_{357}$ cells. (G) Western blotting results of the (H) expression levels of tumor stem cell marker genes CD44, Oct-4 and Nanog in ALDH' and ALDH ${ }^{+} \mathrm{HSC}-3$ cells. ${ }^{*} \mathrm{P}<0.05,{ }^{* * *} \mathrm{P}<0.01,{ }^{* * *} \mathrm{P}<0.001$ vs. Control; ${ }^{\wedge} \mathrm{P}<0.01,{ }^{\wedge \wedge} \mathrm{P}<0.001$ vs. ALDH'. ALDH, aldehyde dehydrogenase; HNSCC, head and neck squamous cell carcinoma.

cat. no. 210210; Qiagen $\mathrm{GmbH}$ ) at $37^{\circ} \mathrm{C}$ for $15 \mathrm{~min}$ and $85^{\circ} \mathrm{C}$ for $5 \mathrm{sec}$. The RT-qPCR experiment was performed as follows: Initial denaturation at $95^{\circ} \mathrm{C}$ for $10 \mathrm{~min}$; denaturation at $95^{\circ} \mathrm{C}$ for $15 \mathrm{sec}$ and annealing at $60^{\circ} \mathrm{C}$ for $1 \mathrm{~min}$ for a total of 40 cycles, and a final extension step at $60^{\circ} \mathrm{C}$ for 1 min using the SYBR Green mixture (cat. no. A25742; Applied Biosystems; 
Thermo Fisher Scientific, Inc.) and a PCR Bio-Rad Chromo 4 system (Bio-Rad Laboratories, Inc.). The reference gene was either GAPDH or U6. The reaction was repeated three times in total, and data were statistically analyzed using a modified $2^{-\Delta \Delta \mathrm{Cq}}$ method (25). The primers used were as follows $\left(5^{\prime}-3^{\prime}\right)$ : NORAD, [forward (F): TGATAGGATACATCTTGGACAT GGA, reverse (R): AACCTAATGAACAAGTCCTGACAT ACA]; MMP-2, (F: TACAGGATCATTGGCTACACACC, R: GGTCACATCGCTCCAGACT); MMP-9, (F: TCTATGGT CCTCGCCCTGAA, R: CATCGTCCACCGGACTCAAA); E-cadherin, (F: CGAGAGCTACACGTTCACGG, R: GGGTG TCGAGGGAAAAATAGG); N-cadherin,(F: TCAGGCGTCT GTAGAGGCTT, R: ATGCACATCCTTCGATAAGACTG); Vimentin,(F: GACGCCATCAACACCGAGTT,R: CTTTGTC GTTGGTTAGCTGGT); miR-26a-5p, (F: TTCAAGTAATCC AGGATAGGCT, R: TATCCAGTGCGTGTCGTGGA); GAPDH,(F: AGCTCCCAAAAATAGACGCAC, R: TTCATA GCAGTAGGCACAAAGG); and U6, (F: CTCGCTTCGGCA GCACA, R: AACGCTTCACGAATTTGCGT).

Statistical analysis. Statistical analysis was performed using GraphPad Prism 8.0 (GraphPad Software, Inc.) and SPSS 20.0 (IBM Corp.). The measurement data are presented as the mean \pm SD of three or more experiments, and were analyzed using an unpaired t-test. The independent-sample t-test was used for comparison between two groups of data, one-way ANOVA was used for analysis among multiple groups followed by Tukey's or Dunnett's tests for pairwise comparison between groups. $\mathrm{P}<0.05$ was considered to indicate a statistically significant difference.

\section{Results}

Isolation and identification of tumor stem cells from HNSCC cell lines. In order to study the possible mechanism in $\mathrm{HNSCC}, \mathrm{ALDH}^{-}$and $\mathrm{ALDH}^{+}$cells were sorted from H357 and HSC-3 cell lines using flow cytometry (Fig. 1A). Then, the self-renewal capacity of $\mathrm{ALDH}^{-}$and $\mathrm{ALDH}^{+}$cells was separately examined. It was found that $\mathrm{ALDH}^{+}$cells could form cell microspheres again, suggesting that $\mathrm{ALDH}^{+}$cells had a self-renewal capacity (Fig. 1B). Moreover, comparisons of ALDH protein expression levels among control, $\mathrm{ALDH}^{-}$and $\mathrm{ALDH}^{+}$cells, were conducted and the results indicated that expression of ALDH in $\mathrm{ALDH}^{-}$cells was significantly lower compared with that in control $(\mathrm{P}<0.01)$ and $\mathrm{ALDH}^{+}$groups $(\mathrm{P}<0.001)$; ALDH protein expression levels were highest in the $\mathrm{ALDH}^{+}$group (Fig. 1C and D).

The positive expression of CD44, Oct-4 and Nanog is considered to be a marker for tumor stem cells (11). The results demonstrated that the expression levels of CD44, Oct-4 and Nanog were significantly higher in $\mathrm{ALDH}^{+}$cells compared with those in $\mathrm{ALDH}^{-}$cells $(\mathrm{P}<0.01$; Fig. $1 \mathrm{E}-\mathrm{H})$.

IncRNA NORAD affects the tumor characteristics of HNSCC tumor stem cells. To investigate the specific role of NORAD in HNSCC tumor stem cells, the effects of overexpression or knockdown of NORAD on tumor stem cell marker genes in $\mathrm{ALDH}^{-}$and $\mathrm{ALDH}^{+}$cells were examined. The expression of NORAD was significantly increased in $\mathrm{ALDH}^{-}$(H357 and HSC-3) cells after transfection with overexpression plasmid ( $\mathrm{P}<0.01$; Fig. $2 \mathrm{~A})$, while the mRNA expression of NORAD in $\mathrm{ALDH}^{+}$cells transfected with siNORAD was significantly decreased, compared with the siNORAD-siNC and Blank groups ( $<<0.01$; Fig. 2B). In $\mathrm{ALDH}^{-}$cells, overexpression of NORAD slightly increased the expression levels of stem cell markers, but there was no significant statistical significance ( $P>0.05$; Fig. 2C-F). On the contrary, knockdown of NORAD significantly downregulated the expression levels of CD44, Oct-4 and Nanog in $\mathrm{ALDH}^{+}$cells $\left(\mathrm{P}<0.05\right.$; Fig. 2G-J). Therefore, $\mathrm{ALDH}^{+}$, CD $44^{+}, \mathrm{Oct}_{-} 4^{+}$and $\mathrm{Nanog}^{+}$cells were selected for subsequent experiments.

Using functional experiments, it was identified that NORAD knockdown significantly decreased cell viability and promoted apoptosis $(\mathrm{P}<0.05$; Fig. 3A-C). Additionally, the migratory and invasive rates of the siNORAD group were lower compared with those of the siNORAD-siNC group $(\mathrm{P}<0.05$; Fig. 3D-G).

lncRNA NORAD targeted to $\mathrm{miR}-26 \mathrm{-}-5 \mathrm{p}$ regulates the viability and apoptosis of HNSCC tumor stem cells. Using bioinformatics, it was identified that NORAD was bound to miR-26a-5p (Fig. 4A). Furthermore, compared with IC, the miR-26a-5p I increased luciferase activity, thereby verifying the prediction that NORAD could bind to miR-26a-5p ( $\mathrm{P}<0.001$; Fig. 4B).

Subsequently, the miR-26a-5p I and siNORAD lentiviral vectors were separately transfected or co-transfected into HNSCC tumor stem cells. It was found that the expression of NORAD was decreased and the expression of miR-26a-5p was increased in the siNORAD group compared with the siNC group ( $\mathrm{P}<0.001$, Fig. 4C and D). However, compared with the siNORAD group, the siNORAD+I group displayed a significant decrease in the expression of miR-26a-5p $(\mathrm{P}<0.001)$, while the expression of NORAD did not markedly change ( $P>0.05)$ (Fig. 4C and D). Furthermore, the results of functional experiments demonstrated that the knockdown of miR-26a-5p partially counteracted the effect of siNORAD, as it promoted cell viability and reduced the apoptotic rates $(\mathrm{P}<0.05$; Fig. 4E-G).

lncRNA NORAD knockdown attenuates the migration, invasion and expression levels of EMT-related proteins in HNSCC tumor stem cells via miR-26a-5p. Previous studies have reported that silencing NORAD inhibits cell migration (26-28), but whether it serves a role by regulating the downstream gene miR-26a-5p has not yet been completely determined. Thus, wound healing assay and Transwell were performed. The results demonstrated that miR-26a-5p I promoted migration and increased the number of invading cells. Moreover, the regulation of the migratory and invasive rates of the siNORAD+I group was reversed compared with the siNORAD group $(\mathrm{P}<0.05$; Fig. 5A-F). Compared with the siNORAD-siNC group, the siNORAD group had lower expression levels of MMP-2, MMP-9, N-cadherin and vimentin, and higher expression of E-cadherin, and the regulation trend of EMT-related genes in group I was opposite to that in the siNORAD group $(\mathrm{P}<0.05$; Fig. 6A-F). Furthermore, the miR-26a-5p I partially offset the regulatory function of siNORAD ( $\mathrm{P}<0.05$; Fig. 6A-F). 

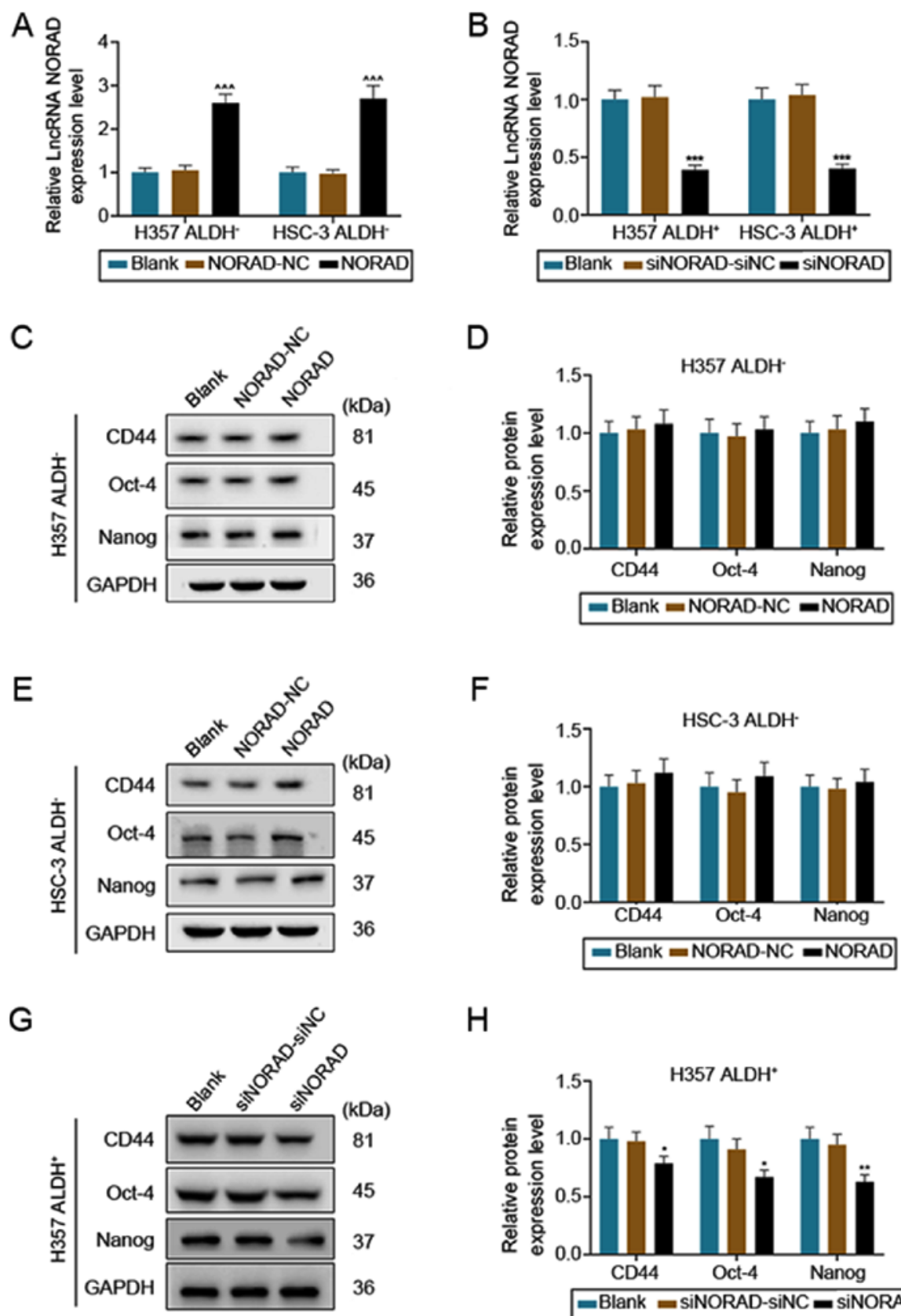

$\mathrm{H}$
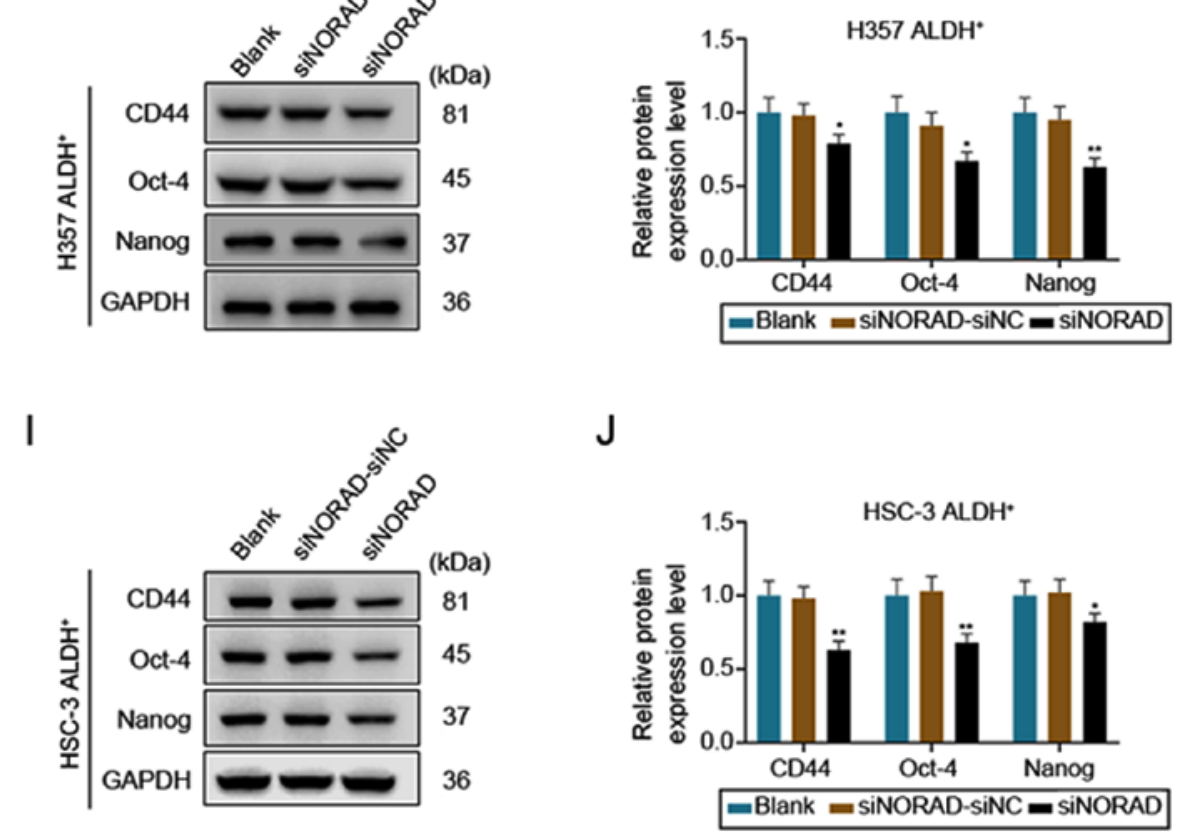

Figure 2. Overexpression and knockdown of NORAD affects the expression levels of stem cell markers in H357 and HSC-3 cell lines. Transfection efficiencies of (A) overexpression and (B) siRNA vector were measured using reverse transcription-quantitative PCR. (C) Western blotting was used to detect the effect of NORAD overexpression on the expression levels of CD44, Oct-4 and Nanog in from H357 ALDH' cells. (D) Relative protein expression levels in H357 $\mathrm{ALDH}^{-}$cells. (E) Western blotting was used to detect the effect of NORAD overexpression on the expression levels of CD44, Oct-4 and Nanog in HSC-3 ALDH ${ }^{-}$cells. (F) Relative protein expression levels in HSC-3 ALDH ${ }^{-}$cells. (G) Western blotting was used to detect the effect of NORAD knockdown on the expression levels of CD44, Oct-4 and Nanog in $\mathrm{H}_{357} \mathrm{ALDH}^{+}$cells. (H) Relative protein expression levels in $\mathrm{H} 357 \mathrm{ALDH}^{+}$cells. (I) Western blotting was used to detect the effect of NORAD knockdown on the expression levels of CD44, Oct-4 and Nanog in HSC-3 ALDH ${ }^{+}$cells. (J) Relative protein expression levels in HSC-3 ALDH ${ }^{+}$cells. GAPDH was used as a control. ${ }^{\wedge \wedge} \mathrm{P}<0.001$ vs. NORAD-NC; ${ }^{*} \mathrm{P}<0.05,{ }^{* *} \mathrm{P}<0.01,{ }^{* * *} \mathrm{P}<0.001$ vs. siNORAD-siNC. NC, negative control; siRNA, small interfering RNA; NORAD, non-coding RNA activated by DNA damage; ALDH, aldehyde dehydrogenase; lncRNA, long non-coding RNA. 


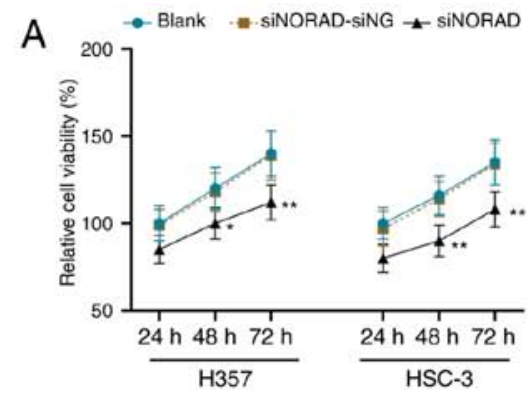

C
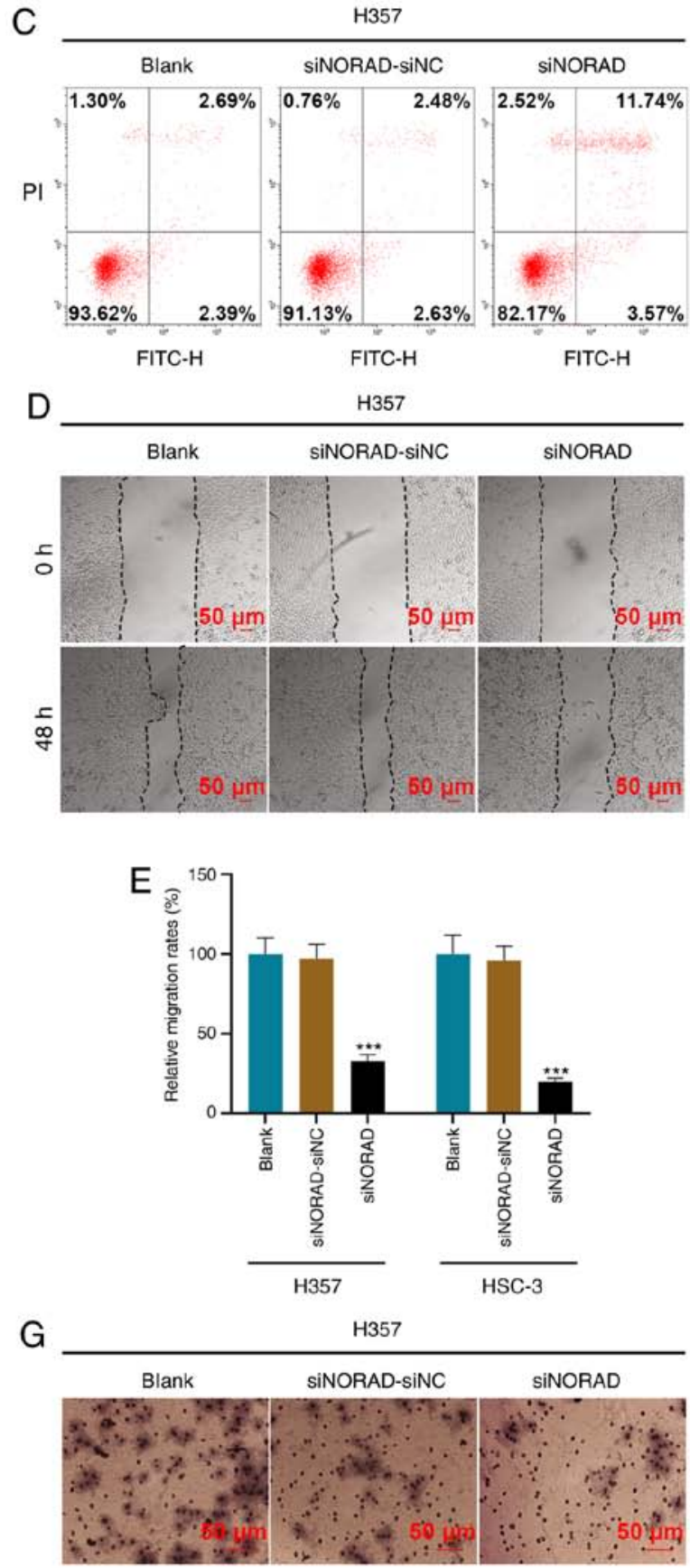
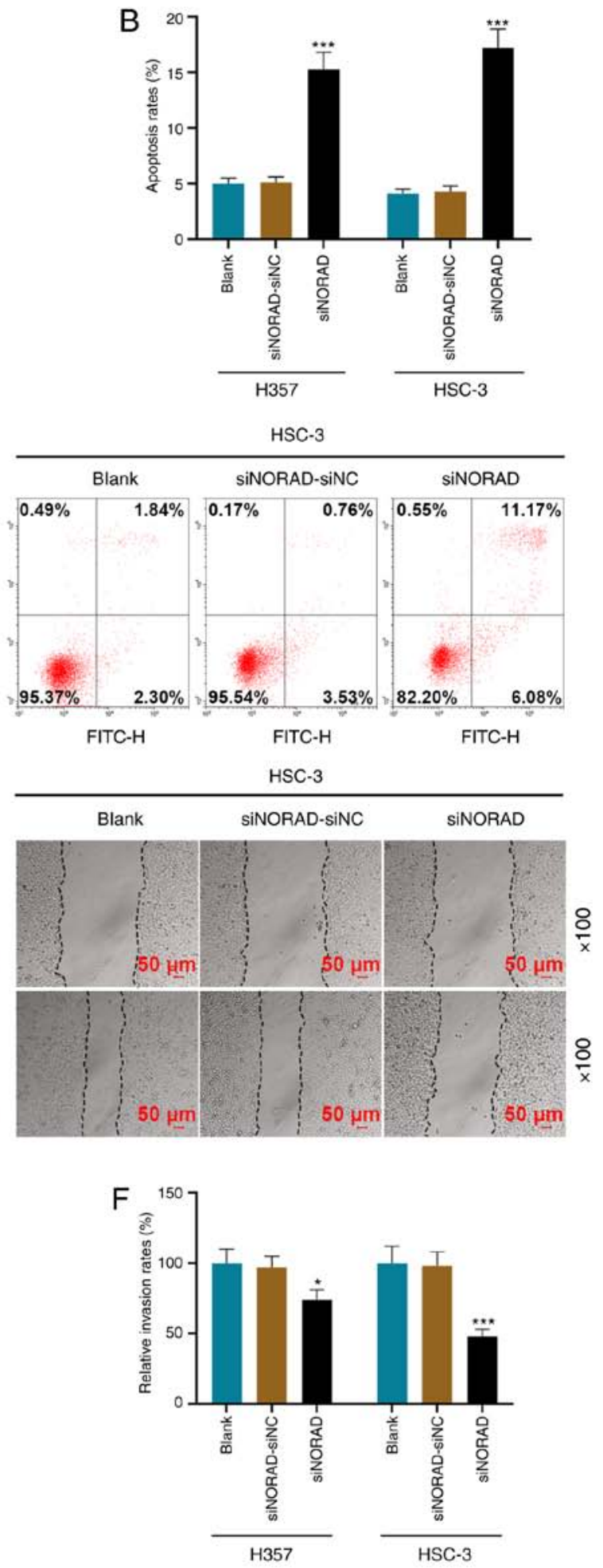

HSC-3

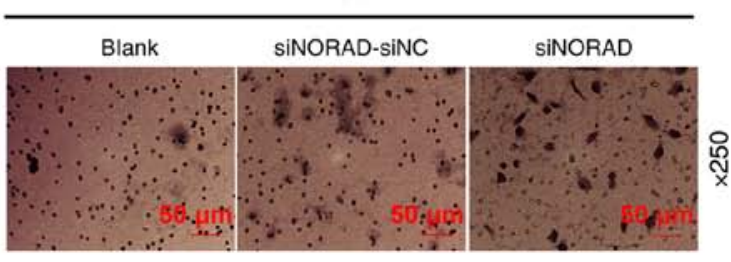

Figure 3. NORAD knockdown affects the tumor characteristics of HNSCC tumor stem cells. (A) siNORAD inhibited the viability of HNSCC tumor stem cells, which was detected using a MTT assay. (B) Results of the (C) flow cytometry, which was used to detect the effect of lncRNA NORAD silencing on the apoptosis of HNSCC tumor stem cells. (D) A wound healing assay was used to measure the (E) cell migration rate of the Blank, siNORAD-NC and siNORAD groups; magnification, $\mathrm{x} 100$. (F) Cell invasion rate of each group was measured using a (G) Transwell assay; magnification, $\mathrm{x} 250)$. ${ }^{*} \mathrm{P}<0.05,{ }^{* *} \mathrm{P}<0.01,{ }^{* * *} \mathrm{P}<0.001$ vs. siNORAD-siNC. HNSCC, head and neck squamous cell carcinoma; NC, negative control; siRNA, small interfering RNA; NORAD, non-coding RNA activated by DNA damage. 

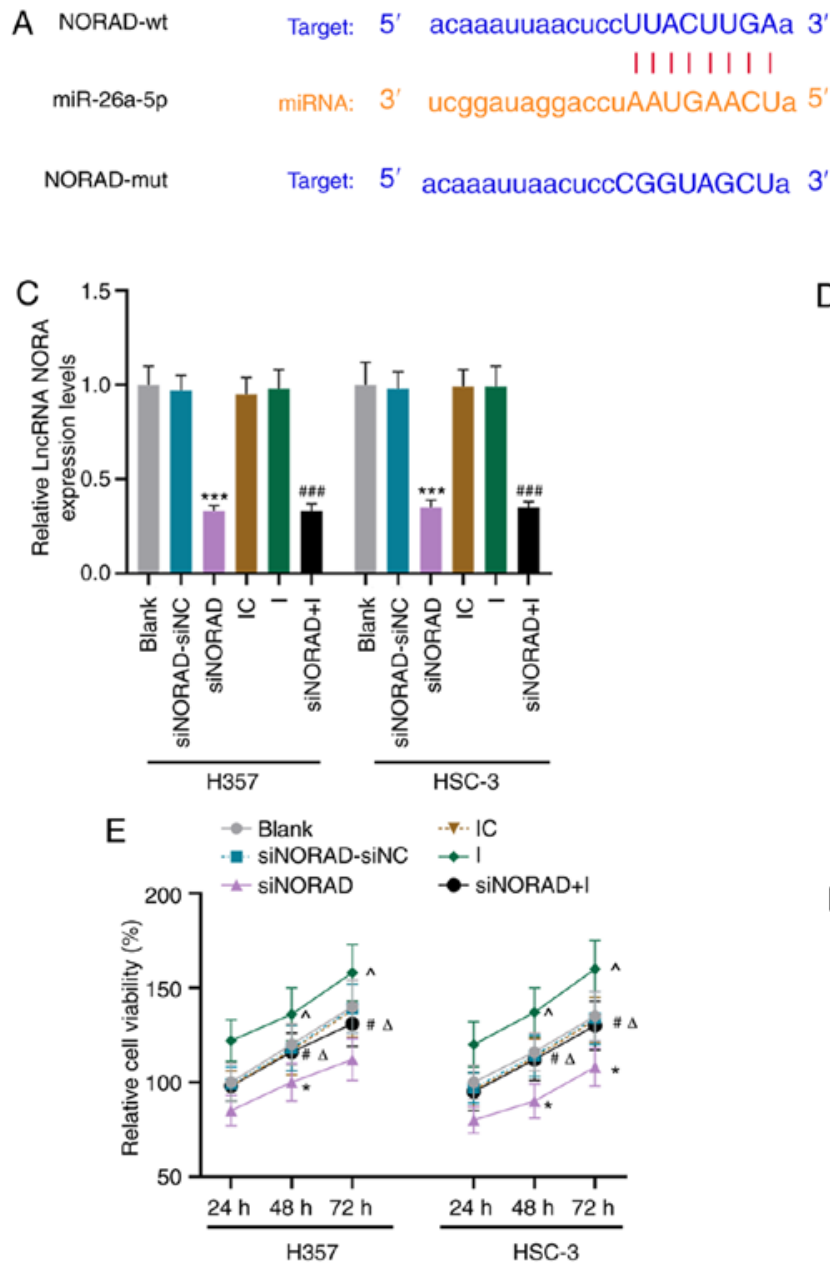
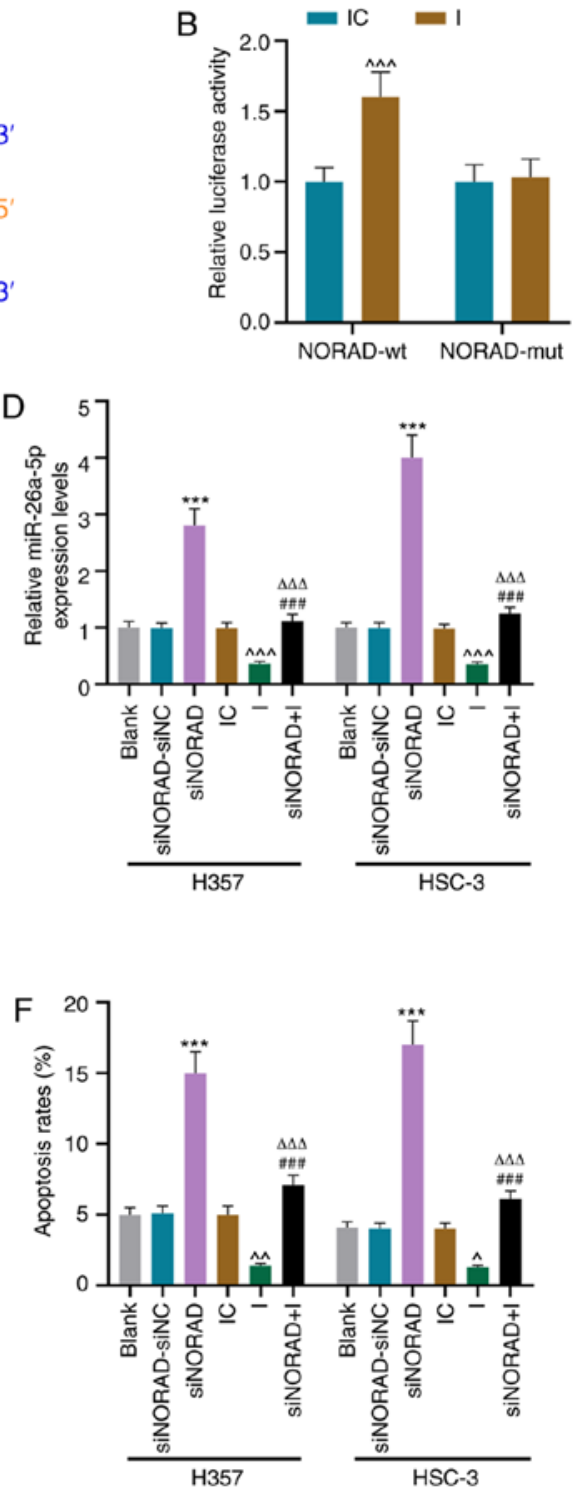

$\mathrm{H} 357$
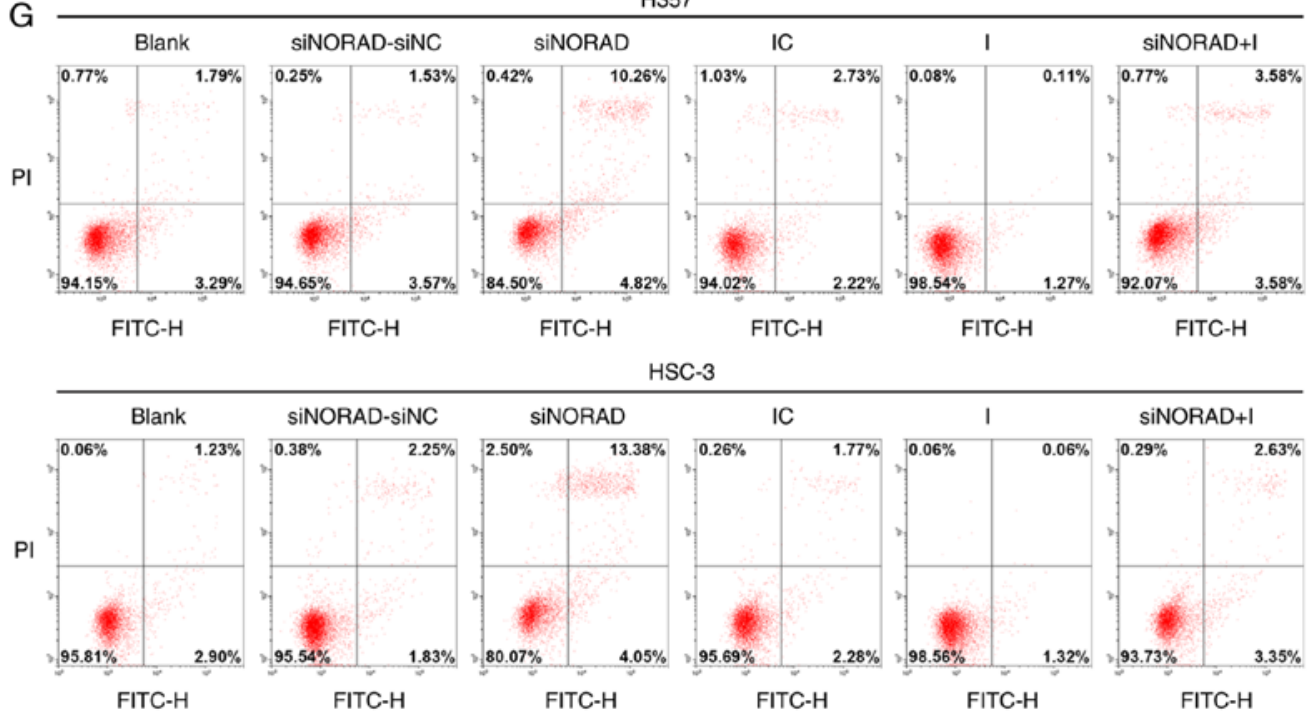

Figure 4. IncRNA NORAD targeted to miR-26a-5p regulates the viability and apoptosis of tumor stem cells in HNSCC. (A) The Encyclopedia of RNA Interactomes website (http://starbase.sysu.edu.cn/) predicted, and (B) the dual luciferase report assay verified the targeting relationship between lncRNA NORAD and miR-26a-5p. Reverse transcription-quantitative PCR was used to determine the expression levels of (C) lncRNA NORAD and (D) miR-26a-5p in the Blank, siNORAD-siNC, siNORAD, IC, I and siNORAD+I groups. (E) Viability of tumor stem cells in each group was detected using the MTT method. (F) miR-26a-5p partially offset the effect of siNORAD on apoptosis, as determined via (G) flow cytometry. ${ }^{*} \mathrm{P}<0.05,{ }^{* * * *} \mathrm{P}<0.001 \mathrm{vs}$. siNORAD-siNC; ${ }^{\wedge} \mathrm{P}<0.05,{ }^{\wedge} \mathrm{P}<0.01,{ }^{\wedge \wedge} \mathrm{P}<0.001$ vs. IC; ${ }^{\#} \mathrm{P}<0.05,{ }^{\# \#} \mathrm{P}<0.001$ vs. I; ${ }^{\Delta} \mathrm{P}<0.05,{ }^{\Delta \Delta \Delta} \mathrm{P}<0.001$ vs. siNORAD. I, miR-26a-5p inhibitor; IC, inhibitor control; NC, negative control; siRNA, small interfering RNA; NORAD, non-coding RNA activated by DNA damage; lncRNA, long non-coding RNA; wt, wild-type; mut, mutant; miR, microRNA. 


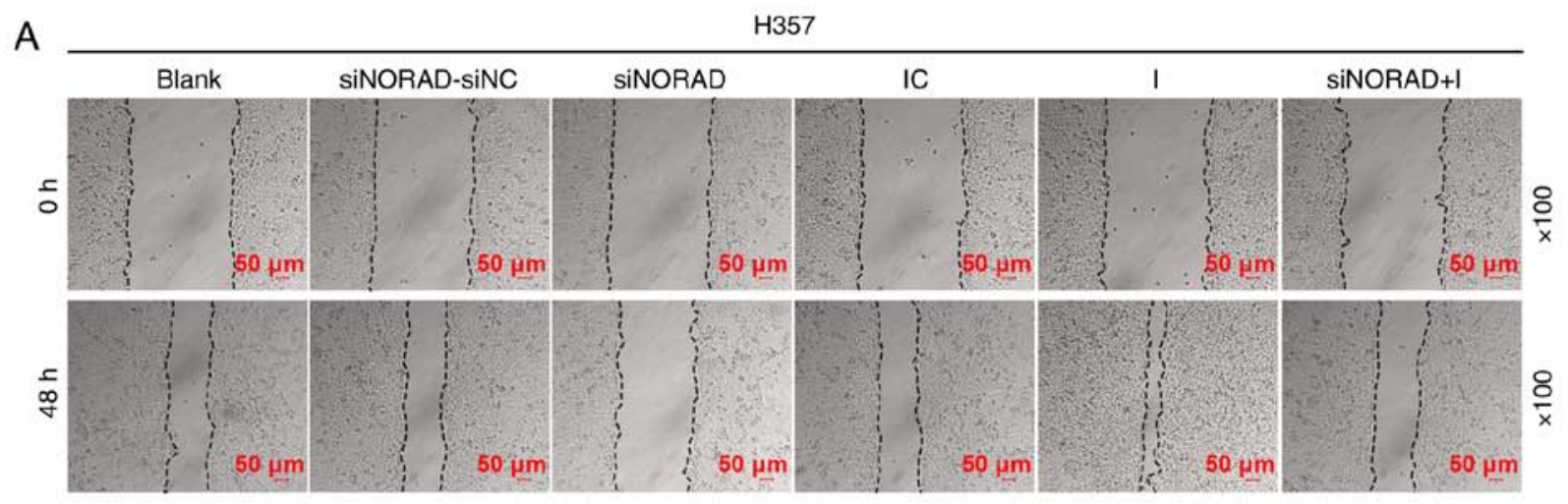

B
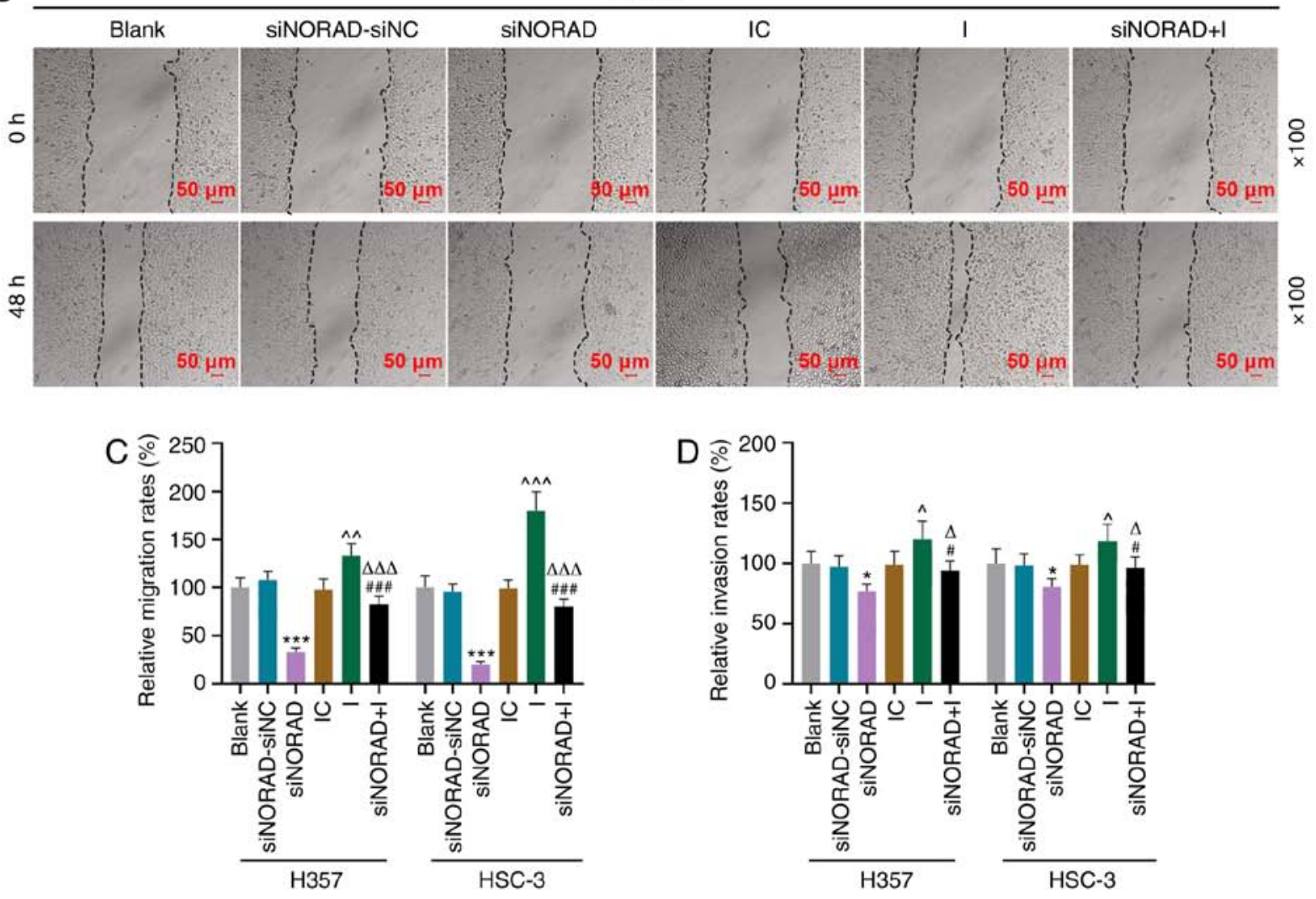

E

H357

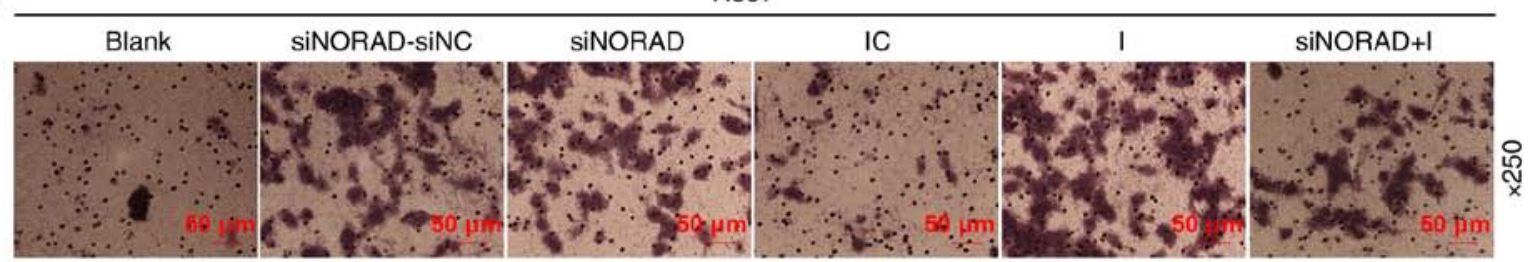

$\mathrm{F}$

HSC-3

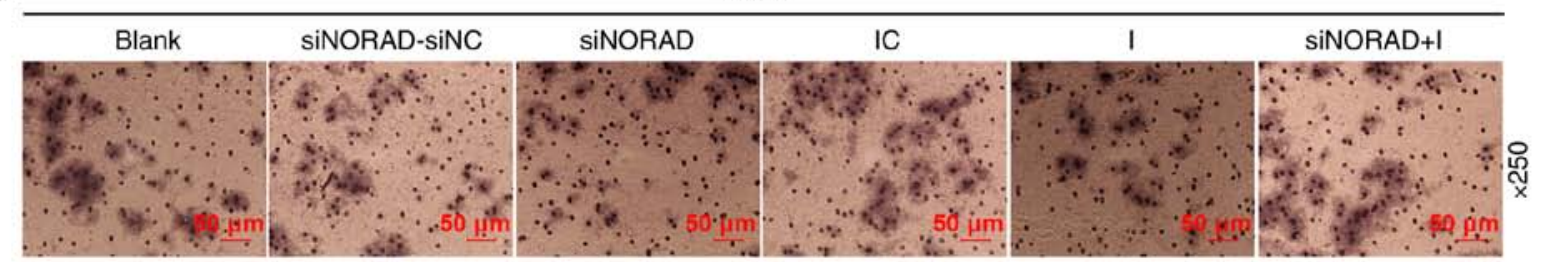

Figure 5. Long non-coding RNA NORAD knockdown decreases the migration and invasion of tumor stem cells via miR-26a-5p in HNSCC. Wound healing assay results from (A) H357 and (B) HSC-3 cells indicating the migration distances of the Blank, siNORAD-siNC, siNORAD, IC, I and siNORAD+I groups; magnification, $x 100$. (C) Relative migration rates are presented as bar diagrams. (D) Number of invasive tumor stem cells in each group was determined using Transwell assays in (E) H357 and (F) HSC-3 cells; magnification, $\mathrm{x} 250$ ). ${ }^{\circ} \mathrm{P}<0.05,{ }^{* * *} \mathrm{P}<0.001$ vs. siNORAD-siNC; ${ }^{\wedge} \mathrm{P}<0.05,{ }^{\wedge} \mathrm{P}<0.01,{ }^{\wedge \wedge} \mathrm{P}<0.001$ vs. IC; ${ }^{\#} \mathrm{P}<0.05$, ${ }^{\# \# \# "} \mathrm{P}<0.001$ vs. I; ${ }^{\circ} \mathrm{P}<0.05,{ }^{\Delta \Delta \Delta} \mathrm{P}<0.001$ vs. siNORAD. I, microRNA-26a-5p inhibitor; IC, inhibitor control; NC, negative control; siRNA, small interfering RNA; NORAD, non-coding RNA activated by DNA damage. 
A
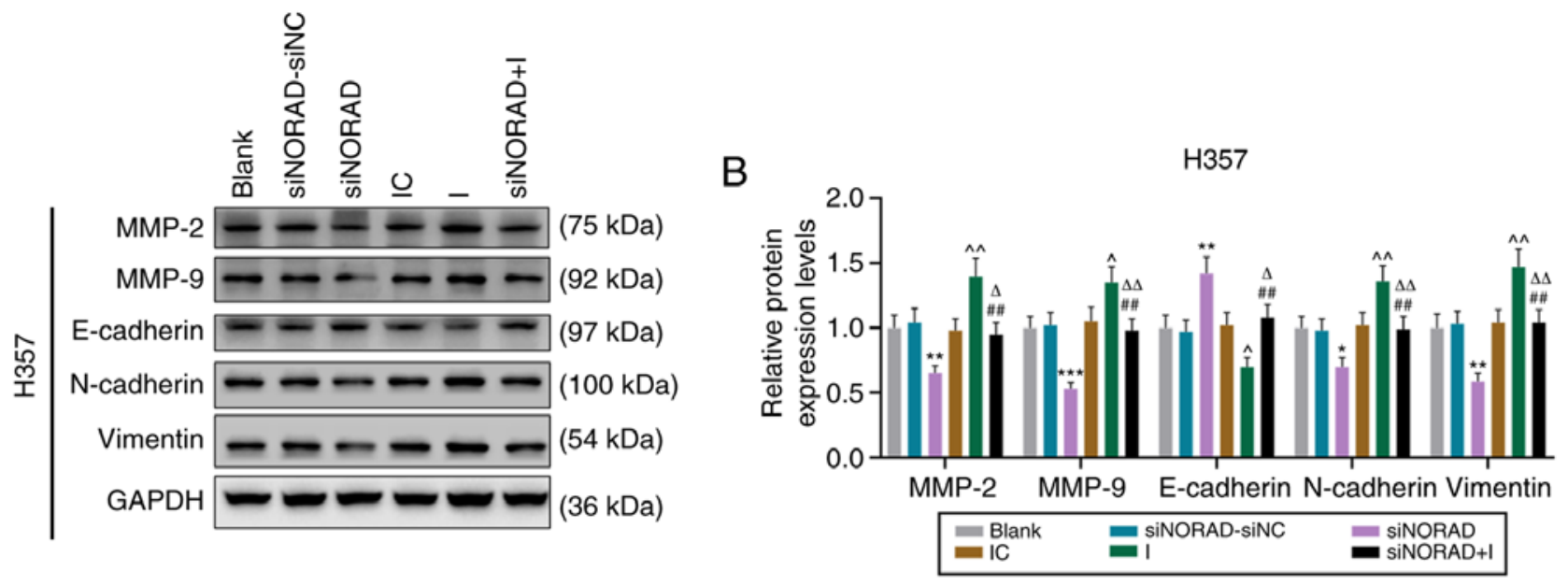

C

$\mathrm{H} 357$
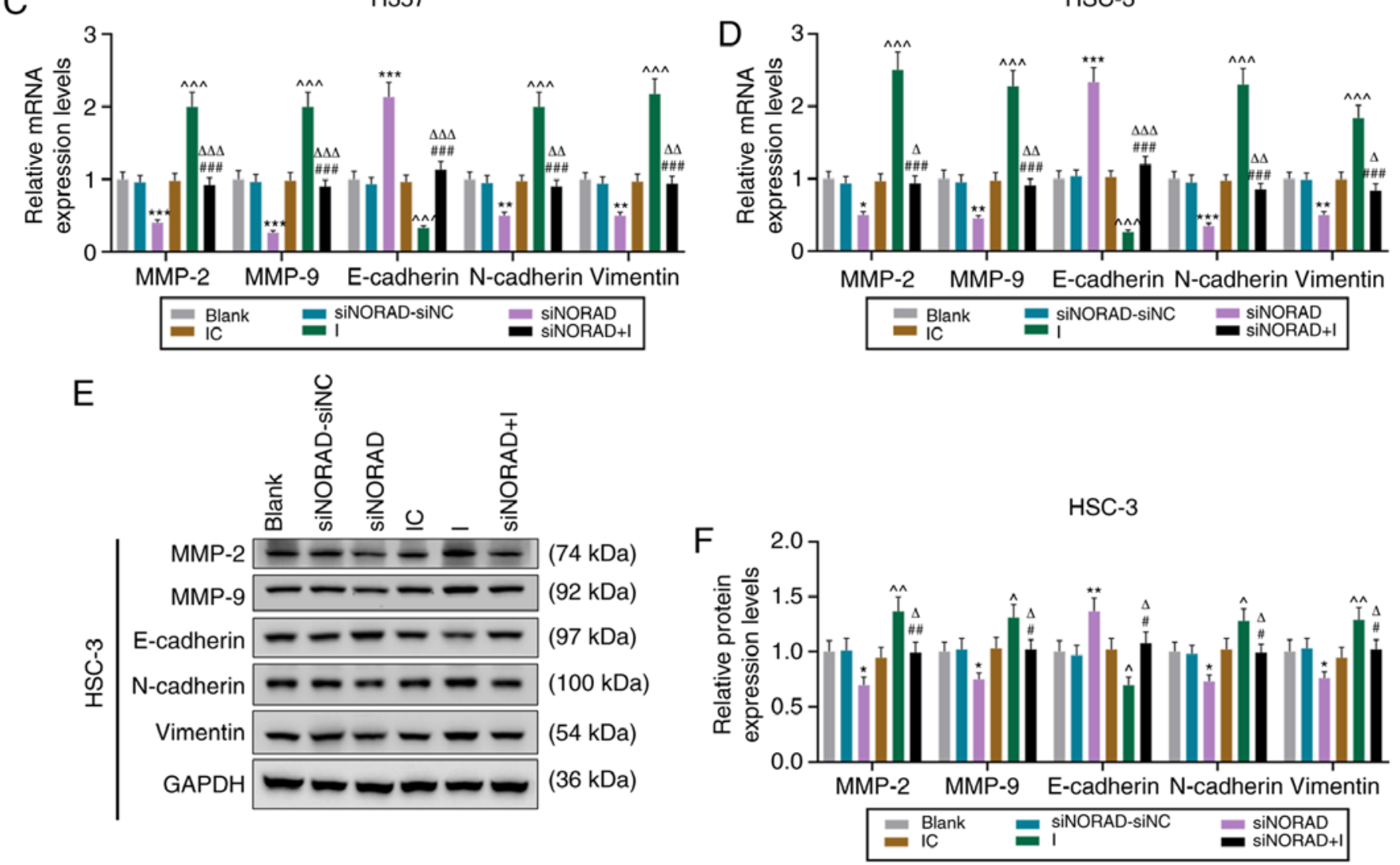

Figure 6. IncRNA NORAD knockdown attenuates the expression of EMT-related proteins in HNSCC tumor stem cells via miR-26a-5p. (A) Western blot analysis was used to detect the expression of MMP-2, MMP-9, E-cadherin, N-cadherin and Vimentin, and (B) relative protein expression is presented as bar diagrams in $\mathrm{H} 357$ cells. Reverse transcription-quantitative PCR was used to determine the mRNA expression of MMP-2, MMP-9, E-cadherin, N-cadherin and Vimentin in (C) H357 and (D) HSC-3 cells. (E) Western blot analysis was used to detect the expression of MMP-2, MMP-9, E-cadherin, N-cadherin and Vimentin, and (F) relative protein expression is presented as bar diagrams in HSC-3 cells. ${ }^{*} \mathrm{P}<0.05,{ }^{* * *} \mathrm{P}<0.01,{ }^{* * * *} \mathrm{P}<0.001$ vs. siNORAD-siNC; ${ }^{\wedge} \mathrm{P}<0.05,{ }^{\wedge} \mathrm{P}<0.01$, ${ }^{\wedge \wedge} \mathrm{P}<0.001$ vs. IC; ${ }^{\#} \mathrm{P}<0.05,{ }^{\# \#} \mathrm{P}<0.01,{ }^{\# \# \#} \mathrm{P}<0.001$ vs. I; ${ }^{\circ} \mathrm{P}<0.05,{ }^{\Delta} \mathrm{P}<0.01,{ }^{\Delta \Delta \Delta} \mathrm{P}<0.001$ vs. siNORAD. I, microRNA-26a-5p inhibitor; IC, inhibitor control; NC, negative control; siRNA, small interfering RNA; NORAD, non-coding RNA activated by DNA damage.

\section{Discussion}

Cancer stem cells have been reported to be closely associated with tumor metastasis and poor prognosis $(5,10)$. The existence of tumor stem cells in HNSCC has also been confirmed in the present research. The present results suggested that the HNSCC cell line can be sorted into $\mathrm{ALDH}^{+}$cells, and that $\mathrm{ALDH}^{+}$cells can form cell microspheres again, suggesting that there are tumor stem cells with self-renewal and pluripotent differentiation in HNSCC cells. Although $\mathrm{ALDH}^{+}$is considered to be a highly specific HNSCC stem cell marker (29), whether ALDH alone is sufficient for the recognition of HNSCC tumor stem cells remains to be further studied. Therefore, the present study used a variety of stem cell molecular surface markers, such as CD44, Oct-4 and Nanog, to make an identification, which is also conducive to obtaining HNSCC tumor stem cells of higher purity (24). 
With the development and application of microarray chips and other technologies, the number of expression profiles of HNSCC-related non-coding RNAs is increasing (30). Abnormally expressed miRNA can not only be used for early diagnosis of HNSCC, but also have certain guiding significance for tumor metastasis and prognostic monitoring, which may provide novel ideas for targeted therapy (31). For example, overexpression of miR-96-5p leads to increased cell migration and radiation resistance and chemotherapy resistance in HNSCC cells by targeting PTEN to activate the PI3K/Akt/mTOR signaling pathway (32). Furthermore, Liu et al (33) identified 128 abnormally expressed miRNAs in HNSCC tissues, and suggested that hsa-miR-383, hsa-miR-615 and hsa-miR-877 may be used as diagnostic markers.

As for miR-26a, which was the primary focus of the present study, research on this miRNA has achieved certain results; for example, it has been suggested that miR-26a may have a role as a biomarker for small extracellular vesicles and as a modulator of excitatory neurotransmission $(34,35)$. However, with regards to HNSCC, especially on the regulation of stem cell stemness and epithelial-mesenchymal function, there is still a lack of relevant research. The latest report revealed that miR-26a overexpression inhibited cell migration via PAK1 and suppressed tumor formation in tongue squamous cell carcinoma (36). The present study demonstrated that miR-26a-5p silencing promoted cell viability, invasion and migration, which is in line with previous results (37). Unlike the previous study, however, the present study found that the upstream target gene of miR-26a-5p may be lncRNA NORAD, according to the prediction of bioinformatics, suggesting that NORAD mediates the stemness of HNSCC stem cells via miR-26a-5p.

A previous study revealed that NORAD was abnormally expressed in gastric cancer samples, and miR-214 interfered with the proliferation of gastric cancer cells (38). In the current study, as expected, knockdown of NORAD significantly downregulated the expression levels of stem cell markers, and siRNA-targeted NORAD had a significant regulatory effect on the biological characteristics of HNSCC tumor stem cells. Furthermore, the miR-26a-5p I counteracted the effect of siNORAD on HNSCC tumor stem cells.

EMT is an important cause of tumor metastasis, and increasing evidence has shown that EMT and stem cells are also closely related (39). May et al (40) reported that when EMT occurs in human breast epithelial cells, there will be the subsequent high expression of stem cell-related factors. Moreover, a study of patients with pancreatic cancer found that the occurrence of EMT is often accompanied by the activation of stem cell-related channels (41). A previous study has also reported that, compared with primary tumor cells, the expression levels of EMT-related markers in stem cells are significantly increased. Furthermore, these markers are downregulated in epithelial cells but have increased expression in mesenchymal cells (42). EMT not only promotes the metastasis and invasion of tumor cells, but also affects the drug resistance and enrichment of stem cells (43). The present results also suggested that NORAD regulated the expression levels of EMT-related proteins in stem cells via miR-26a-5p.

However, there is a limitation to the present study. Although it was demonstrated that the miR-26a-5p I could notably promote the migration and invasion of HNSCC stem cells, the effects of miR-26a-5p overexpression on the EMT progression of cancer cells require further investigation.

In conclusion, the present study demonstrated that NORAD interfered with the malignant phenotype and EMT of HNSCC stem cells by inhibiting miR-26a-5p. The present research provides a novel insight into the molecular regulatory network of HNSCC stem cells, but these findings should be further clarified in in vivo experiments and in additional downstream pathway studies.

\section{Acknowledgements}

Not applicable.

\section{Funding}

This work was supported by the Zhejiang Provincial Department of Medicine and Health Project (grant no. 2018247374) and the Zhejiang Traditional Chinese Medicine Science and Technology Plan Project (grant no. 201823105013221).

\section{Availability of data and materials}

The analyzed data sets generated during the study are available from the corresponding author on reasonable request.

\section{Authors' contributions}

Substantial contributions to conception and design: WH and YZ. Data acquisition, data analysis and interpretation: LS, ZW, WJ, XJ and ML. Drafting the article or critically revising it for important intellectual content: $\mathrm{WH}$ and $\mathrm{YZ}$. All authors agreed to be accountable for all aspects of the work in ensuring that questions related to the accuracy or integrity of the work are appropriately investigated and resolved. All authors read and approved the final manuscript.

\section{Ethics approval and consent to participate}

Not applicable.

\section{Patient consent for publication}

Not applicable.

\section{Competing interests}

The authors declare that they have no competing interests.

\section{References}

1. Svider PF, Blasco MA, Raza SN, Shkoukani M, Sukari A, Yoo GH, Folbe AJ, Lin HS and Fribley AM: Head and Neck Cancer. Otolaryngol Head Neck Surg 156: 10-13, 2017.

2. Mendez LC, Moraes FY, Poon I and Marta GN: The management of head and neck tumors with high technology radiation therapy. Expert Rev Anticancer Ther 16: 99-110, 2016.

3. Solomon B, Young RJ and Rischin D: Head and neck squamous cell carcinoma: Genomics and emerging biomarkers for immunomodulatory cancer treatments. Semin Cancer Biol 52: 228-240, 2018. 
4. Mermod M, Tolstonog G, Simon C and Monnier Y: Extracapsular spread in head and neck squamous cell carcinoma: A systematic review and meta-analysis. Oral Oncol 62: 60-71, 2016.

5. Chang JC: Cancer stem cells: Role in tumor growth, recurrence, metastasis, and treatment resistance. Medicine (Baltimore) 95 (Suppl 1): S20-S25, 2016.

6. Nandy SB and Lakshmanaswamy R: Cancer Stem Cells and Metastasis. Prog Mol Biol Transl Sci 151: 137-176, 2017.

7. Zhou H and Xu R: Leukemia stem cells: The root of chronic myeloid leukemia. Protein Cell 6: 403-412, 2015.

8. Leão R, Domingos C, Figueiredo A, Hamilton R, Tabori U and Castelo-Branco P: Cancer Stem Cells in Prostate Cancer: Implications for Targeted Therapy. Urol Int 99: 125-136, 2017.

9. Curtarelli RB, Gonçalves JM, Dos Santos LGP, Savi MG, Nör JE, Mezzomo LAM and Rodríguez Cordeiro MM: Expression of Cancer Stem Cell Biomarkers in Human Head and Neck Carcinomas: A Systematic Review. Stem Cell Rev Rep 14: 769-784, 2018.

10. Dawood S, Austin L and Cristofanilli M: Cancer stem cells: Implications for cancer therapy. Oncology (Williston Park) 28 1101-1107, 1110, 2014.

11. Peitzsch C, Nathansen J, Schniewind SI, Schwarz F and Dubrovska A: Cancer Stem Cells in Head and Neck Squamous Cell Carcinoma: Identification, Characterization and Clinical Implications. Cancers (Basel) 11: E616, 2019.

12. Chen YC, Chen YW, Hsu HS, Tseng LM, Huang PI, Lu KH, Chen DT, Tai LK, Yung MC, Chang SC, et al: Aldehyde dehydrogenase 1 is a putative marker for cancer stem cells in head and neck squamous cancer. Biochem Biophys Res Commun 385: 307-313, 2009.

13. Prince MEP, Zhou L, Moyer JS, Tao H, Lu L, Owen J, Etigen M, Zheng F, Chang AE, Xia J, et al: Evaluation of the immunogenicity of ALDH(high) human head and neck squamous cell carcinoma cancer stem cells in vitro. Oral Oncol 59: 30-42, 2016.

14. Ailles L and Prince M: Cancer stem cells in head and neck squamous cell carcinoma. Methods Mol Biol 568: 175-193, 2009.

15. Li J, Liang Y, Lv H, Meng H, Xiong G, Guan X, Chen X, Bai Y and Wang K: miR-26a and miR-26b inhibit esophageal squamous cancer cell proliferation through suppression of c-MYC pathway. Gene 625: 1-9, 2017.

16. Cabello P, Pineda B, Tormo E, Lluch A and Eroles P: The Antitumor Effect of Metformin Is Mediated by miR-26a in Breast Cancer. Int J Mol Sci 17: E1298, 2016.

17. Feng M, Xu D and Wang L: miR-26a inhibits atherosclerosis progression by targeting TRPC3. Cell Biosci 8: 4, 2018.

18. Lin Y, Chen H, Hu Z, Mao Y, Xu X, Zhu Y, Xu X, Wu J, Li S, Mao $\mathrm{Q}$, et al: miR-26a inhibits proliferation and motility in bladder cancer by targeting HMGA1. FEBS Lett 587: 2467-2473, 2013.

19. Deng M, Tang HL, Lu XH, Liu MY, Lu XM, Gu YX, Liu JF and He ZM: miR-26a suppresses tumor growth and metastasis by targeting FGF9 in gastric cancer. PLoS One 8: e72662, 2013.

20. Fukumoto I, Kikkawa N, Matsushita R, Kato M, Kurozumi A, Nishikawa R, Goto Y, Koshizuka K, Hanazawa T, Enokida H, et al Tumor-suppressive microRNAs (miR-26a/b, miR-29a/b/c and miR-218) concertedly suppressed metastasis-promoting LOXL2 in head and neck squamous cell carcinoma. J Hum Genet 61 : 109-118, 2016

21. Zhang XM, Wang J, Liu ZL, Liu H, Cheng YF and Wang T: LINC00657/miR-26a-5p/CKS2 ceRNA network promotes the growth of esophageal cancer cells via the MDM2/p53/Bcl2/Bax pathway. Biosci Rep 40: BSR20200525, 2020.

22. Cheng Y, Wen G, Sun Y, Shen Y, Zeng Y, Du M, Zhu G, Wang $\mathrm{G}$ and Meng $\mathrm{X}$ : Osteopontin Promotes Colorectal Cancer Cell Invasion and the Stem Cell-Like Properties through the PI3K-AKT-GSK/3 $\beta-\beta /$ Catenin Pathway. Med Sci Monit 25 3014-3025, 2019

23. Ghods AJ, Irvin D, Liu G, Yuan X, Abdulkadir IR, Tunici P, Konda B, Wachsmann-Hogiu S, Black KL and Yu JS: Spheres isolated from 9L gliosarcoma rat cell line possess chemoresistant and aggressive cancer stem-like cells. Stem Cells 25: 1645-1653, 2007.

24. Kuo SZ, Honda CO, Li WT, Honda TK, Kim E, Altuna X, Abhold E, Wang-Rodriguez J and Ongkeko WM: Metformin Results in Diametrically Opposed Effects by Targeting Non-Stem Cancer Cells but Protecting Cancer Stem Cells in Head and Neck Squamous Cell Carcinoma. Int J Mol Sci 20: E193, 2019.
25. Livak KJ and Schmittgen TD: Analysis of relative gene expression data using real-time quantitative PCR and the 2(-Delta Delta C(T)) Method. Methods 25: 402-408, 2001.

26. Zhang $\mathrm{H}$ and Guo $\mathrm{H}$ : Long non-coding RNA NORAD induces cell proliferation and migration in prostate cancer. J Int Med Res 47: 3898-3904, 2019.

27. Yu SY, Peng H, Zhu Q, Wu YX, Wu F, Han CR, Yan B, Li Q and Xiang HG: Silencing the long noncoding RNA NORAD inhibits gastric cancer cell proliferation and invasion by the RhoA/ROCK1 pathway. Eur Rev Med Pharmacol Sci 23: 3760-3770, 2019.

28. Huo H, Tian J, Wang R, Li Y, Qu C and Wang N: Long non-coding RNA NORAD upregulate SIP1 expression to promote cell proliferation and invasion in cervical cancer. Biomed Pharmacother 106: 1454-1460, 2018.

29. Toledo-Guzmán ME, Hernández MI, Gómez-Gallegos ÁA and Ortiz-Sánchez E: ALDH as a Stem Cell Marker in Solid Tumors. Curr Stem Cell Res Ther 14: 375-388, 2019.

30. Sannigrahi MK, Sharma R, Panda NK and Khullar M: Role of non-coding RNAs in head and neck squamous cell carcinoma: A narrative review. Oral Dis 24: 1417-1427, 2018.

31. Zou AE, Zheng H, Saad MA, Rahimy M, Ku J, Kuo SZ, Honda TK, Wang-Rodriguez J, Xuan Y, Korrapati A, et al: The non-coding landscape of head and neck squamous cell carcinoma. Oncotarget 7: 51211-51222, 2016.

32. Vahabi M, Pulito C, Sacconi A, Donzelli S, D'Andrea M, Manciocco V, Pellini R, Paci P, Sanguineti G, Strigari L, et al: miR-96-5p targets PTEN expression affecting radio-chemosensitivity of HNSCC cells. J Exp Clin Cancer Res 38: 141, 2019.

33. Liu C, Yu Z, Huang S, Zhao Q, Sun Z, Fletcher C, Jiang Y and Zhang D: Combined identification of three miRNAs in serum as effective diagnostic biomarkers for HNSCC. EBioMedicine 50: 135-143, 2019.

34. Tormo E, Adam-Artigues A, Ballester S, Pineda B, Zazo S, González-Alonso P, Albanell J, Rovira A, Rojo F, Lluch A, et al: The role of miR-26a and miR-30b in HER2 $2^{+}$breast cancer trastuzumab resistance and regulation of the CCNE2 gene. Sci Rep 7: 41309, 2017

35. Lafourcade CA, Fernández A, Ramírez JP, Corvalán K, Carrasco MÁ, Iturriaga A, Bátiz LF, Luarte A and Wyneken U: A Role for mir-26a in Stress: A Potential sEV Biomarker and Modulator of Excitatory Neurotransmission. Cells 9: E1364, 2020.

36. Wei Z, Chang K, Fan C and Zhang Y: miR-26a/miR-26b represses tongue squamous cell carcinoma progression by targeting PAK1. Cancer Cell Int 20: 82, 2020.

37. Li Y, Wang P, Wu LL, Yan J, Pang XY and Liu SJ: miR-26a-5p Inhibit Gastric Cancer Cell Proliferation and Invasion Through Mediated Wnt5a. OncoTargets Ther 13: 2537-2550, 2020

38. Tao W, Li Y, Zhu M, Li C and Li P: lncRNA NORAD Promotes Proliferation And Inhibits Apoptosis Of Gastric Cancer By Regulating miR-214/Akt/mTOR Axis. OncoTargets Ther 12: 8841-8851,2019.

39. Zhang Y and Weinberg RA: Epithelial-to-mesenchymal transition in cancer: Complexity and opportunities. Front Med 12: 361-373, 2018.

40. May CD, Sphyris N, Evans KW, Werden SJ, Guo W and Mani SA: Epithelial-mesenchymal transition and cancer stem cells: A dangerously dynamic duo in breast cancer progression. Breast Cancer Res 13: 202, 2011.

41. Zhou P, Li B, Liu F, Zhang M, Wang Q, Liu Y, Yao Y and Li D: The epithelial to mesenchymal transition (EMT) and cancer stem cells: Implication for treatment resistance in pancreatic cancer. Mol Cancer 16: 52, 2017.

42. Khan MI, Czarnecka AM, Lewicki S, Helbrecht I, Brodaczewska K, Koch I, Zdanowski R, Król M and Szczylik C: Comparative Gene Expression Profiling of Primary and Metastatic Renal Cell Carcinoma Stem Cell-Like Cancer Cells. PLoS One 11: e0165718, 2016.

43. Shibue T and Weinberg RA: EMT, CSCs, and drug resistance: The mechanistic link and clinical implications. Nat Rev Clin Oncol 14: 611-629, 2017.

This work is licensed under a Creative Commons Attribution-NonCommercial-NoDerivatives 4.0 International (CC BY-NC-ND 4.0) License. 